Finisterra, XXXVII, 73, 2002, pp. 121-123

\title{
EVOLUÇÃO GEOMORFOLÓGICA DO SECTOR TERMINAL DA BACIA DO RIO ALCABRICHEL - LOURINHÃ
}

\author{
JORGE TRINDADE $^{1}$
}

O Rio Alcabrichel tem a sua cabeceira na Serra de Montejunto e desagua na praia de Porto Novo, perto do Vimeiro, no concelho da Lourinhã. Tem uma bacia hidrográfica com cerca de $180 \mathrm{~km}^{2}$, desenvolvida nos materiais da Orla Mesocenozóica Ocidental. O rio tem um traçado complexo, com diversas mudanças de orientação, especialmente no sector vestibular onde entalha a plataforma litoral que atinge $160 \mathrm{~m}$ de altitude e atravessa duas depressões diapíricas.

Os estudos geomorfológicos e geológicos sobre a área são escassos e correspondem a abordagens realizadas a escalas de análise menores do que o trabalho de que aqui se dá notícia ${ }^{2}$ (BReuIL e ZBYszewsKI, 1942-45; RAU e Zbyszewski, 1949; Pereira, M. G., 1971; Daveau, 1973; Manuppella et al., 1999).

A presente dissertação enquadra-se na investigação que tem vindo a ser desenvolvida no litoral estremenho por parte do grupo DILIF e encontra-se dividida em 4 capítulos. Nestes pretende-se sistematizar não só a dinâmica quaternária de um elemento estruturante da paisagem e a influência de determinados factores geomorfológicos na configuração dos vales e vertentes, mas também a influência dessa dinâmica na ocupação humana holocénica da área.

O capítulo introdutório inicia-se com referência aos primeiros trabalhos da evolução quaternária, desenvolvidos na plataforma litoral entre a Lagoa de Óbidos e a Serra de Sintra, dos quais Contribuition à l'étude des industries paléolithiques du Portugal et de leurs rapports avec la géologie quaternaire, de H. BREUIL e G. ZBYSZEWSKi (1942-45) é a primeira obra de fundo. Segue-se a descrição do estado actual dos conhecimentos relativamente ao Quaternário litoral e continental deste sector. É neste capítulo que se introduz ao leitor a área objecto deste estudo, salientando-se a presença da depressão diapírica de Maceira, e se define o objectivo deste trabalho, ou seja, a distinção dos diferentes tipos de

\footnotetext{
1 Investigador da Linha de Investigação DILIF (Dinâmica Litoral e Fluvial), Centro de Estudos Geográficos. E-mail: jorgetrd@univ-ab.pt

2 TRINDADE, J. (2001) - Evolução geomorfológica do sector terminal da bacia do Rio Alcabrichel (A-dos-Cunhados - Praia de Porto Novo) - Lourinhã. Dissertação de Mestrado em Geografia Física e Ambiente apresentada à F.L.U.L. (117 p. polic. + 2 mapas).

Este trabalho apresentado em Dezembro de 2001, decorreu sob a orientação da Professora Ana Ramos Pereira e a sua discussão teve como arguentes a Professora Suzanne Daveau, da Universidade de Lisboa, e a Professora Assunção Araújo, da Universidade do Porto.
} 
formas de relevo, a sua génese e sequência temporal. Referem-se algumas indicações metodológicas associadas ao levantamento de campo, à cartografia geomorfológica e ao tratamento laboratorial das colheitas sedimentológicas.

O segundo capítulo é dedicado ao quadro lito-estrutural da área tratada e ao condicionamento que exerce sobre grande parte das formas de relevo. As rochas detríticas do Jurássico final e do Cretácico encontram-se dispostas em estrutura monoclinal e tabular e afloram em grande parte da área. No entanto, esta monotonia lito-estrutural é quebrada com a presença da depressão diapírica de Maceira que confere ao relevo um arranjo local particular, composto por um anticlinal esventrado e por escarpas de falha formando abruptos. Os calcários compactos do Vimeiro, que assentam sobre as margas evaporíticas de Dagorda, condicionam o aparecimento de formas em barra cujo comando chega a atingir 90m. Resumindo, podemos encontrar na área estudada formas de relevo associadas a estruturas tabulares, monoclinais e dobradas. Esta diferenciação morfo-estrutural sublinha o papel activo da tectónica diapírica na disposição e vigor das formas de relevo.

O terceiro capítulo é dedicado ao estudo dos retalhos planos presentes a diferentes altitudes ao longo de todo o troço vestibular do vale do Rio Alcabrichel. Alguns parecem estar associados à plataforma litoral, outros possuem uma clara génese fluvial, apresentando depósitos correlativos. Salientam-se algumas dificuldades interpretativas associadas à ausência de depósitos discordantes nos níveis superiores e em grande parte dos restantes retalhos planos.

Um dos elementos de terraço que possui o depósito correlativo melhor conservado é o de Casal das Paradas. Esta portela (entre 60 e $65 \mathrm{~m}$ de altitude) corresponde a um fundo de vale abandonado do Rio Alcabrichel e a uma organização da rede hidrográfica completamente diferente da que hoje conhecemos. A forma (talhada em arenitos titonianos) associada ao depósito, que não terá menos de $15 \mathrm{~m}$ de espessura, denuncia um paleovale com uma saída a Sul da actual. Desde logo se coloca a seguinte questão: por que razão o Rio Alcabrichel teria abandonado o seu leito em arenitos brandos para se instalar na depressão diapírica de Maceira, ultrapassando, assim, duas gargantas de calcários compactos (Vimeiro e Porto Novo) que não possuem menos de $60 \mathrm{~m}$ de comando? É então sugerido o papel da tectónica diapírica na reorganização da rede hidrográfica, sendo apresentada uma hipótese evolutiva.

No capítulo seguinte é desenvolvido o estudo de caso da Ribeira de Toledo, afluente do Rio Alcabrichel. A Ribeira de Toledo encontra-se encaixada num vale de fractura e é condicionada estruturalmente pela proximidade do diapiro de Maceira $(<1 \mathrm{~km})$. Tal como a restante bacia do Rio Alcabrichel, esta ribeira possui testemunhos relacionados com o entalhe da rede hidrográfica, nos quais se enquadra o elemento de terraço de Toledo, talhado nos arenitos titonianos do Bombarral. Este encontra-se bem conservado a $30 \mathrm{~m}$ de altitude e, para além de testemunhar um período de estabilidade no entalhe da Ribeira, possui um depósito coluvionar que fossiliza uma ocupação pré-histórica composto por vários horizontes. 
Para estabelecer a relação entre a informação sedimentar e a informação arqueo-zoológica procedeu-se ao tratamento sedimentológico de 80 amostras num perfil de $2 \mathrm{~m}$, do qual se extraíram sedimentos de $5 \mathrm{em} 5 \mathrm{~cm}$. Assim, foi possível distinguir processos associados à dinâmica fluvial e à dinâmica da vertente e extrapolar alguns cenários geomorfológicos, relacionando a informação arqueo-zoológica e as datações absolutas deste horizonte arqueológico com a dinâmica da linha de costa descrita na bibliografia. Por fim, recorreu-se a fontes históricas para salientar a dinâmica da linha de costa nos últimos onze séculos.

O sector hoje ocupado pela praia de Santa Rita e de Porto Novo seria no século IX um sistema lagunar de barreira que permitia a existência de biodiversidade capaz de sustentar uma comunidade de monges beneditinos e a restante população. O sistema lagunar terá, assim, funcionado inicialmente através de processos erosivos, permitindo o aprofundamento da foz nas margas hetangianas de Dagorda. A disponibilidade sedimentar e a ondulação dominante de Noroeste contribuíram para o desenvolvimento de uma restinga ao mesmo tempo que a desflorestação progressiva das áreas circundantes fornecia materiais para o enchimento deste sistema litoral, hoje herdado, que acabou por ser substituído pelo actual sistema de praia-duna.

A presente dissertação demonstra a importância da tectónica diapírica na organização da rede hidrográfica e os problemas interpretativos a ela associados. Demonstra, também, a existência de testemunhos do entalhe dos cursos de água e a sua distribuição no sector terminal da bacia do Rio Alcabrichel, indicando fundos de vale herdados associados a uma rede hidrográfica distinta da actual. Esta área litoral revelou ainda a existência de sistemas litorais herdados desde o último fini-glaciário até ao período histórico.

\section{BIBLIOGRAFIA}

BReuil, H.; ZBYszewSKI, G. (1942-45) - Contribution à l'étude des industries paléolithiques du Portugal et de leurs rapports avec la géologie quaternaire. Comunicações dos Serviços Geológicos de Portugal, 23 e 26, Lisboa.

Daveau, S. (1973) - Quelques exemples d'évolution quaternaire des versants au Portugal. Finisterra-Revista Portuguesa de Geografia. Vol.VIII, (15): 5-47, Lisboa.

Manuppella, G.; Antunes, M; Pais, J.; Ramalho, M.; Rey, J. (1999) - Notícia explicativa da folha 30-A (Lourinhã) da Carta Geológica de Portugal. Esc. 1/50 000. Serviços Geológicos de Portugal, Lisboa.

Pereira, M. G. (1971) - A bacia da Ribeira de Alcabrichel. Contribuição para o seu estudo geomorfológico e sedimentológico. Dissertação de Licenciatura em Geografia Física, Universidade de Lisboa.

Rau, V.; ZByszewski, G. (1949) - Estremadura et Ribatejo (Livret-guide de l'excursion D). XVI Congrès International de Géographie, CEG, Lisboa. 